\title{
Design of Naca63215 Airfoil for a Wind Turbine
}

\author{
${ }^{1}$ N.Manikandan, ${ }^{2}$ B.Stalin \\ Department of Mechanical Engineering P. A. College of Engineering and Technology, Pollachi-2. Coimbatore, \\ Tamilnadu, India. \\ Assistant Professor, Department of Mechanical Engineering Anna University Regional center, Madurai. \\ Madurai, Tamilnadu,India.
}

\begin{abstract}
The ultimate objective of the work is to increase the reliability of wind turbine blades through the development of the airfoil structure and also to reduce the noise produced during the running period of the wind turbine blades. The blade plays a pivotal role, because it is the most important part of the energy absorption system. Consequently, the blade has to be designed carefully to enable to absorb energy with its greatest efficiency. In this work, Pro/E, Hypermesh software has been used to design blades effectively. NACA 63-215 airfoil profile is considered for analysis of wind turbine blade. The wind turbine blade is modeled and several sections are created from root to tip with the variation from the standard design for improving the efficiency. For the further improvement required in the efficiency of the wind turbine the winglet is to be included at the tip of the blade which would help in increasing the efficiency and reducing the noise produced from the blades in working condition. The existing turbine blade and the modified blade with the winglet are compared for their results.
\end{abstract}

Keywords: Wind Turbine Blades, Airfoil, Computational Fluid Dynamics, Winglet, Noise

\section{Introduction}

A significant amount of exhaustive research has been done in the area of small and medium scale wind turbine blades and most of them have used the classical blade element momentum theory for designing the blades and calculating the forces acting on it. Lot of research on finding the optimum chord lengths has been made using a variety of evolutionary optimizing techniques. Some work that forms the background for this research is as follows [1]. Jackson, et.al made a preliminary design of a 50 meters long blade, two versions one of fiber glass and one with carbon composite was used to test the cost and thickness of cross sections was changed in order to improve structural efficiency. The aerodynamic performance was made using computational techniques and the computations were predicted using clean and soiled surface [2].Karam and Hani optimized using the variables as cross section area, radius of gyration and the chord length, the optimal design is for maximum natural frequency. The optimization is done using multi dimensional search techniques. The results had shown the technique was efficient [3].K.J. Johansen, and Sorensen N.N, modified the tip of the rotors to winglet to improve the aerodynamic performance of turbine rotors and to make them less sensitive to wind gusts [4]. Maughmer, M.D, tilted the blade tip to the effect of winglets which decreases the induced drag of the blade by changing the downwash distribution, hence increasing the power production [5].Mickael Edon had designed a blade for 38 meters for a 1.5MW power using the BEM theory, and had suggested in his future work the chord distribution formula which I have implemented. Since his blade was close to my design I choose the same airfoil profile [6]. M. Jureczko, M. Pawlak, A. Mezyk used the BEM theory to design and used ANSYS for calculation of natural frequencies. They had found out the mode shape of the blades by using the Timoshenko twisted tapered beam element theory. The genetic algorithm was used to minimize blade vibration, maximize output, minimize blade cost and increase stability [7].Philippe Giguere and Selig had described blade geometry optimization for the design of wind turbine rotors, pre-programmed software was used to optimize structures and cost model [8].

Tingting Guo, Dianwen Wu, Jihui Xu, Shaohua Li developed a 1.5 MW turbine rotor of 35 meters blade length, using Matlab programming for designing and concluded the feasibility of Matlab for designing large wind turbines, further they had also compared with CFD results and the found out Matlab was economical in artificial design and optimizing for efficiency [9]. Wang Xudong, et al used three different wind turbine sizes in order to optimize the cost based on maximizing the annual energy production for particular turbines at a general site. In their research using a refined BEM theory, an optimization model for wind turbines based on structural dynamics of blades and minimizes the cost of energy. Effective reduction of the optimization was documented [10].Z.L. Mahri and Rouabah had calculated the dynamic stresses on a blade which was designed the blade element theory. The rotor diameter was 10 meters and the dynamic analysis was made using the beam theory and the modal analysis is made using the finite element modeling and also using the blade motion equation [11]. 
This present work is done in designing a wind turbine blade using the Blade Element Theory for a length of 1.5 meters which is suitable for $2.0 \mathrm{KW}$ small wind turbine. The chord lengths are calculated and the chord distributions, flow angles, the differential power, thrust and torque are all at discrete intervals of the blade are plotted. The blade is then assumed to be a tapered hollow beam. The natural frequency is found out by solving the Eigen value problem. The blade efficiency can be increased by attaching a winglet to the end of the blade. The winglets are normally used in the aerospace vehicle designs.

\section{AIRFOILS AND BLADE GEOMETRY}

\section{Design Considerations}

In order to select a main blade to conduct the most extensive part of the optimization,random winglet configurations are taken from the design parameters range table. A blade is selected to perform more extensive optimization experiments after implementing a winglet. Selecting a single blade avoids having to implement the winglet in three different blades, reducing the experiment time outrageously. There are many different types of airfoils used for wind turbine rotor blades.

Some researchers have used blended wings using two different types of airfoils in order to achieve the desired design. Such a design is shown in Figure 1.

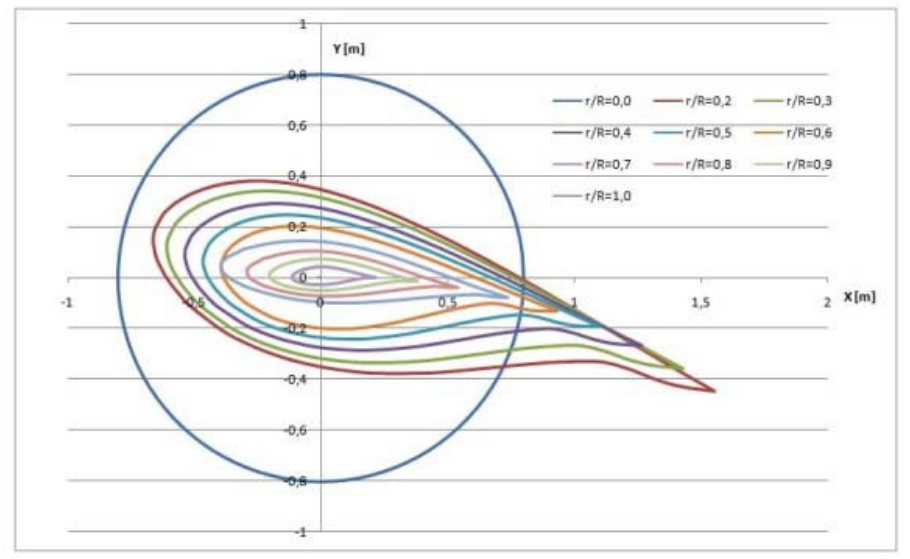

Figure 1 Blade profiles from NACA 63-430 and NACA 63-215.

As it can be observed, the NACA series airfoils are quite popular in this type of application. However, it has been shown that these airfoils have noticeable performance degradation from roughness effects resulting from leading-edge contamination. This leads to energy losses which can be of great importance for stallregulated rotors. The National Renewable Energy Laboratory (NREL) began its development of new airfoils specific for wind turbine application. The annual energy improvements from the NREL airfoil families are worked to be $23 \%$ to $35 \%$ for stall-regulated turbines, $8 \%$ to $20 \%$ for variable-pitch turbines and $8 \%$ to $10 \%$ for variable-rpm turbines.

\subsection{DESIGN OF WINGLET DESIGN}

The geometry of a winglet is defined by six parameters

- Height

- Sweep angle

- Cant angle

- Curvature radius

- Toe angle

- Twist angle

The geometry of winglets has been extensively investigated for the aeronautical industry and specifically for high performance sailplanes. Since it has been shown that winglets decrease drag and improve aerodynamic performance of wind turbine rotor blades, it is important to understand and analyze the design and performance improvement process that these researchers used for this application. This gives a good overview and provides with ideas on how to manage the design process for the wind turbine application. 

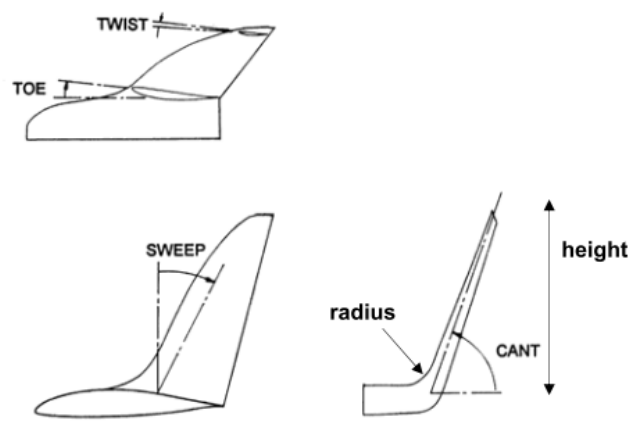

Figure 2. Parameters describing winglet geometry.

These geometric parameters can serve as the variables for input to the optimization algorithm in order to find the optimal shape given the aerodynamic constraints and goals.

\subsection{DESIGN COMPONENTS}

In order to completely test any winglet design and notice to prove any improvements delivered from winglet design alternatives, the design must be tested on an existing wind turbine configuration for which power output, aerodynamic and operational data are known or can be found.The proposed wind turbine to conduct all aerodynamics and structural studies consists of an upwind tri-blade horizontal axis turbine, with a rotor diameter $\mathrm{D}=3.2 \mathrm{~m}$, rotor height $\mathrm{h}=7.62 \mathrm{~m}$, power output of approximately $2 \mathrm{~kW}$, tip speed ratio of $4-10$, at a wind speed of $0-5 \mathrm{~m} / \mathrm{s}$. Based on this design, the blades are changed and tested, and winglets are implemented and tested.

To attain maximum power generation from a wind turbine, the correct and optimized design of the blades is necessary. An optimal blade features a maximum lift coefficient for which roughness has no effect. It is also a goal of the airfoil family to reach the minimum $\mathrm{C}_{\mathrm{d}} / \mathrm{C}_{1}$ possible. Through the length of an optimal blade, different airfoil shapes are present. Usually, 3 to 5 different airfoil shapes are distributed along a blade, and the distance between them depends on the behavior of the flow around each individual airfoil at a radial position from the rotor center.

In the extent of this work, three different families of airfoils are tested for best performance, with and without a winglet. From a specified rotor diameter, wind speed and range of tip speed ratio, and a random selection of two winglet configurations, the three blade configurations are tested for maximum $C_{l}$. The best performing blade featuring a winglet is to be used for further winglet design optimization; however, final optimized designs are to be tested in all three blades. The airfoil families to be used in this work have been extracted from various sources, including a paper from the National Renewable Energy Laboratory (NREL) and Airfoils Inc., and the RISO DTU National Laboratory for Sustainable Energy.

\subsection{THEORETICAL DESIGN}

\subsubsection{BLADE PITCH ANGLE}

A critical part of the rotor design includes the selection of either a variable speed ratio or a fixed speed ratio, and this is determined by either implementing a variable blade pitch system or selecting a fixed blade pitch angle. For the purpose of this work, a fixed blade pitch angle is chosen.

Recalling previous definitions, the tip speed ratio is defined as the ratio between the blade tip speed and the wind speed. Since the wind speed in a regular environment is a variable phenomenon, it is physically right to say that having a fixed blade pitch angle produces a variable tip speed ratio. An optimal blade pitch angle is attained by means of BEM and later optimized through CFD.

\subsubsection{BLADE TWIST ANGLE}

A variable angle of attack through the length of the blade is given by a specified twist angle. The distribution of the twist angle is based on the aerodynamic behavior $\left(C_{d} / C_{1}\right.$ and other parameters $)$ of each individual airfoil at a certain angle of attack. This angle of attack is then translated to the angle of relative wind by adding the initial twist angle of the blade. Equation yields to the angle of relative wind $\varphi$.

$$
\begin{array}{r}
\varphi=\left(\frac{2}{3}\right) \tan ^{-1}\left(\frac{1}{\lambda_{r}}\right) \\
\text { Where, } \\
\lambda_{\mathrm{r}} \text { is the local speed ratio, } \\
\varphi \text { is the blade twist angle. }
\end{array}
$$


The distribution of the twist angle is given in the proposed design, and it is equal to $\varphi$ minus the angle of attack $\alpha$.

\subsubsection{CHORD DISTRIBUTION}

The chord length of each airfoil in a blade is also variable, and it is obtained with Equation

$$
c=\left(\frac{8 \pi r}{B C_{l}}\right)(1-\cos \varphi)
$$

Where,

$B$ is the number of blades.

The distribution of the chord length is given in the proposed design.

\subsubsection{PROPOSED INITIAL DESIGN}

The design of the blade has been preliminarily performed using Q-blade, available wind turbine blade design software which works together with X-foil in order to design and analyze a blade with different airfoils for each cross section as well as twist angle along the length of the blade.The parameters for the design of the blade were taken from a student design optimization in which a wind turbine blade was optimized using several methodologies including design of experiments (DOE), gradient-based sequential quadratic programming optimization and a multi objective genetic algorithm. The objective functions of this optimization work are to maximize the power output while minimizing the blade volume and structural stress. The chosen blade radius is $1.6 \mathrm{~m}$, and in the airfoil used is 63 series especially 63-215, 63-215 (Modified), $63-415$.

Given that the purpose of this work is the design of airfoil and winglets, the blade design will be based upon the findings of this real time work. In order to have an original blade design for this work, the following NACA airfoil family was used for the blade geometry. Table 2 shows the configuration for a medium to large blade length recommended by NACA. Unlike typical airfoils used in aeronautics, these airfoils have been specifically designed for wind turbines. The camber in these airfoils is higher than others, it can be observed that the thickness of the blade is higher at its root, and decreases along its length, until the thinnest airfoil is used at the tip.

Table 1 Airfoils for blade design

\begin{tabular}{|c|c|c|c|c|c|c|}
\hline $\begin{array}{c}\text { Blade } \\
\text { Length } \\
\text { (m) }\end{array}$ & $\begin{array}{c}\text { Generator } \\
\text { (kW) }\end{array}$ & Thickness & \multicolumn{4}{|c|}{ Airfoil family (root to tip) } \\
\hline $1-3$ & $1.5-5$ & $15-21$ & Rectangle & $63-215$ & $\begin{array}{c}63-215 \\
\text { (modified) }\end{array}$ & $63-415$ \\
\hline
\end{tabular}

The location of the airfoil family along the length of the blade is described in Table 2, where $\mathrm{x}$ is the position from the root to the tip of the blade and $\mathrm{R}$ is the radius of the blade $(1.6 \mathrm{~m})$.

Table 2 Position of airfoils along length of the blade

\begin{tabular}{|c|c|c|}
\hline Airfoil & $\mathbf{x} / \mathbf{R}$ & $\mathbf{x}(\mathbf{m})$ \\
\hline $\mathbf{6 3}-\mathbf{2 1 5}$ & 0.3 & 0.48 \\
\hline $\mathbf{6 3}-\mathbf{2 1 5}$ (Modified) & 0.4 & 0.64 \\
\hline $\mathbf{6 3 - 4 1 5}$ & 0.75 & 1.2 \\
\hline
\end{tabular}

The twist angle, defined as the angle between the airfoil chord length and the plane of the blade rotation, is shown in Table 3. Also, another parameter that is detailed in this table is the chord length of the airfoil. It can be observed that the chore length decreases along the length of the blade. This design technique is called tapering.

Table 3 Parameters for blade design

\begin{tabular}{|c|c|c|c|}
\hline $\mathrm{X}(\mathrm{m})$ & $\mathbf{x} / \mathbf{R}$ & $\begin{array}{c}\text { Twist angle } \\
\text { (deg) }\end{array}$ & $\begin{array}{c}\text { Chord length } \\
\text { (m) }\end{array}$ \\
\hline 0 & 0 & 0 & 0.192 \\
\hline 0.18 & 0.474 & 2.5 & 0.172 \\
\hline 0.36 & 0.643 & 5.0 & 0.151 \\
\hline 0.54 & 0.730 & 7.5 & 0.131 \\
\hline 0.72 & 0.783 & 10.0 & 0.111 \\
\hline 0.90 & 0.818 & 12.5 & 0.091 \\
\hline 1.08 & 0.844 & 15. & 0.070 \\
\hline
\end{tabular}


The design is given as a list of $\mathrm{X}, \mathrm{Y}$ and $\mathrm{Z}$ coordinates of the section airfoil at each $\mathrm{x} / \mathrm{R}$. This enables the user to import each cross section as a curve in a CAD program, a spline is used to connect the point cloud and the part can be created by means of a blend option, such as in Pro Engineer.

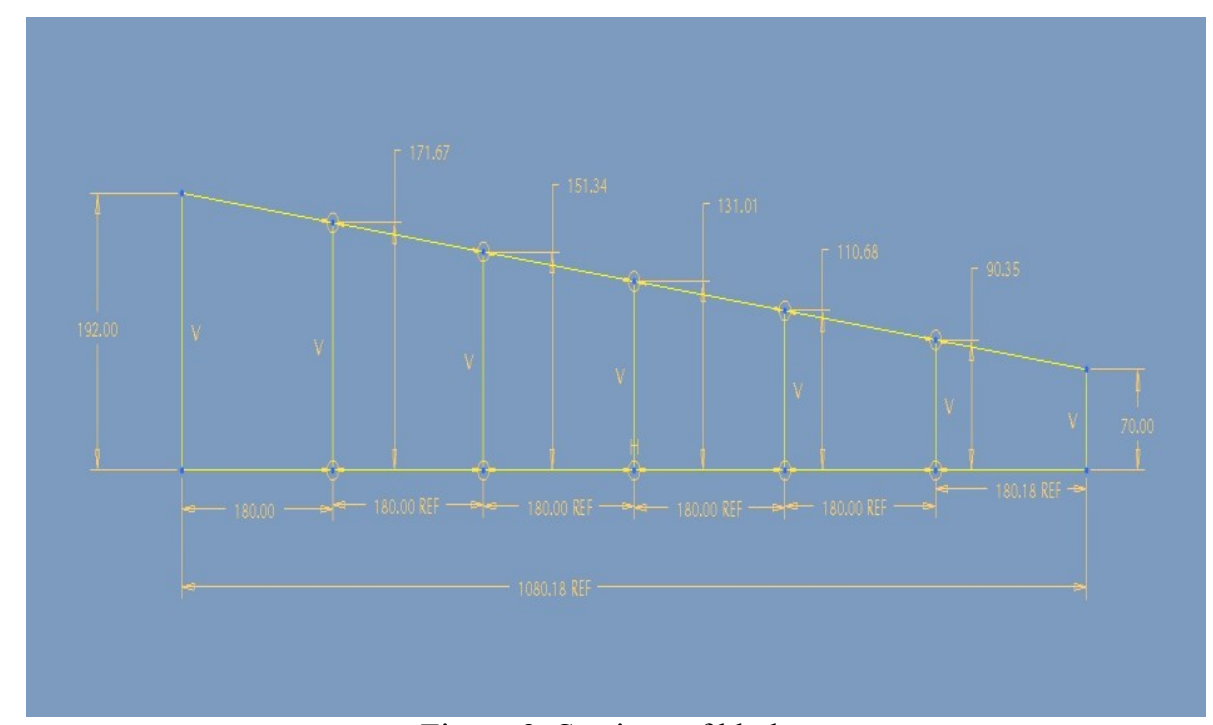

Figure 3. Sections of blade

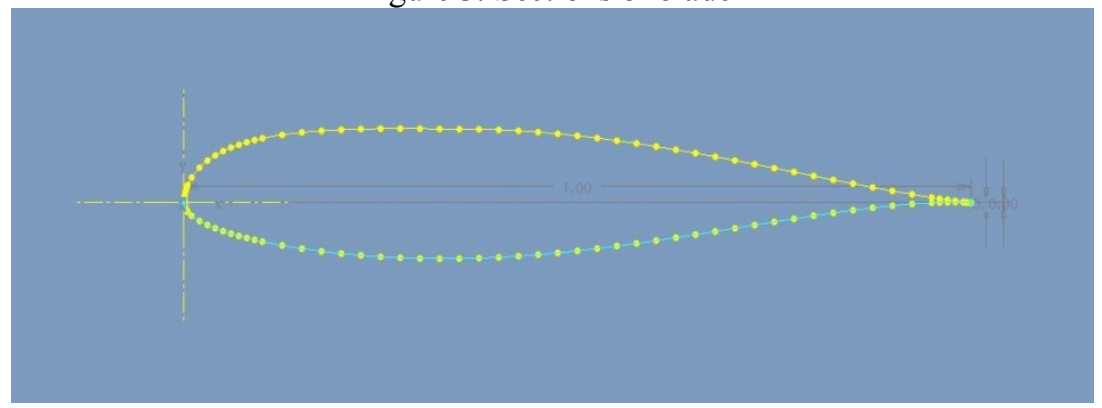

Figure 3. 2D Airfoil in Pro Engineer

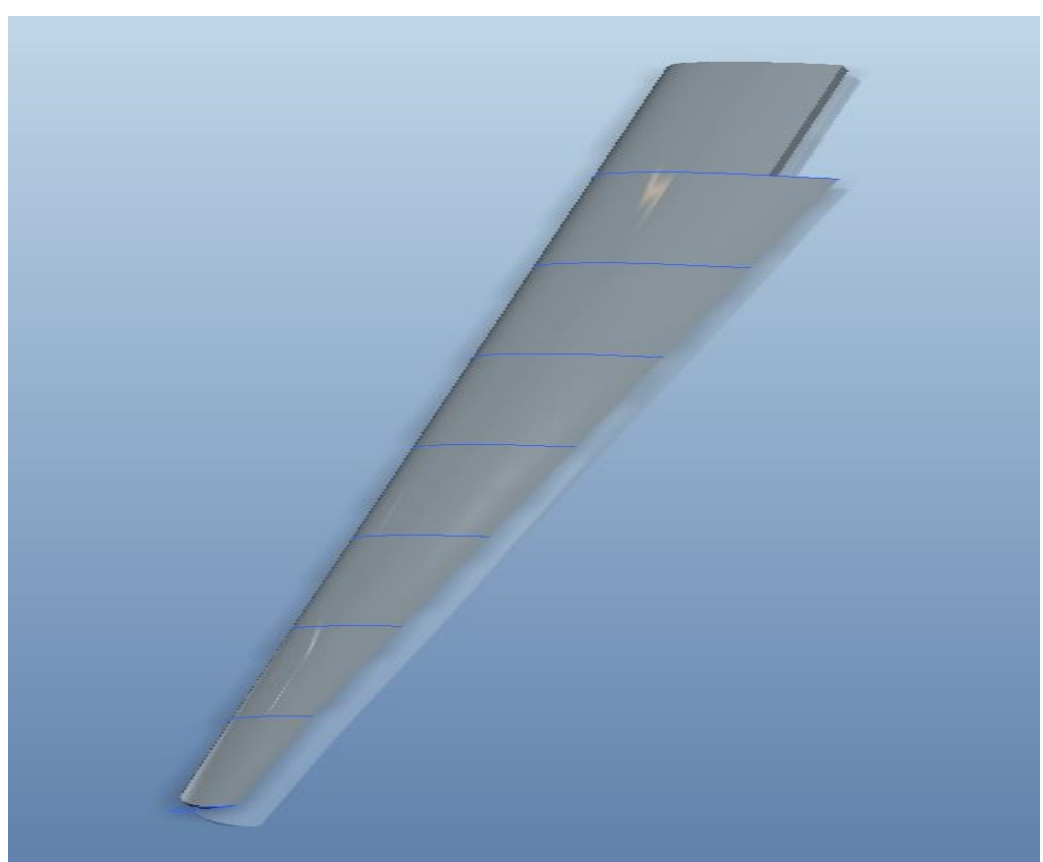

Figure 4.Curves in blade 


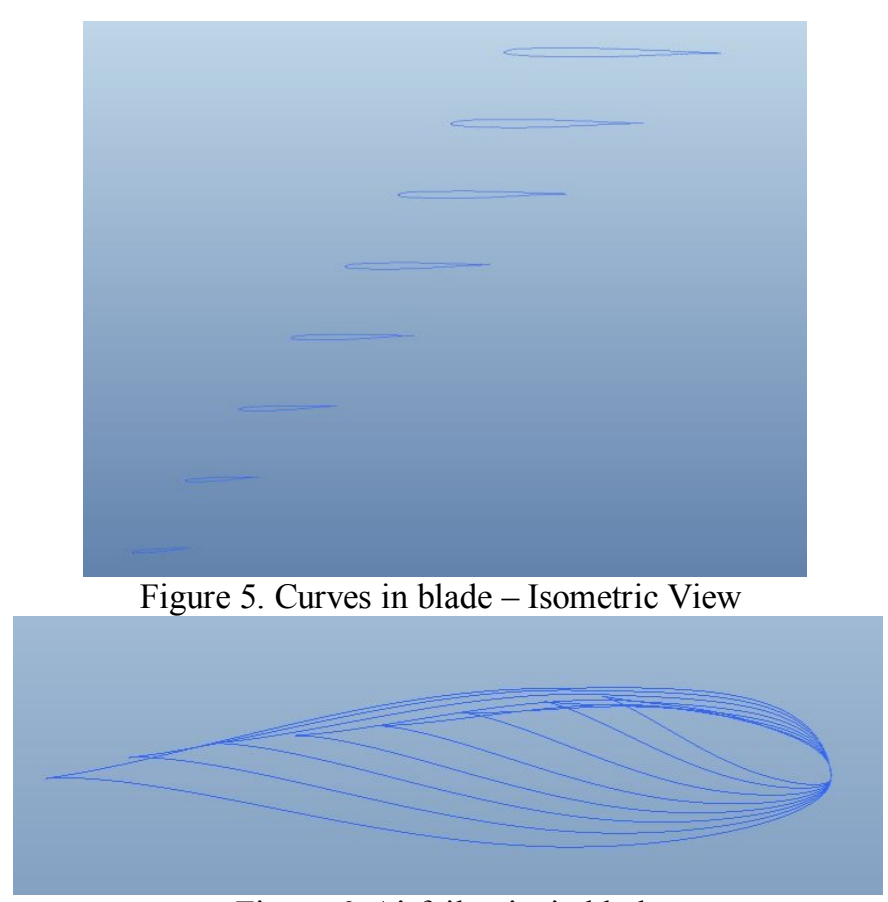

Figure 6. Airfoil twist in blade

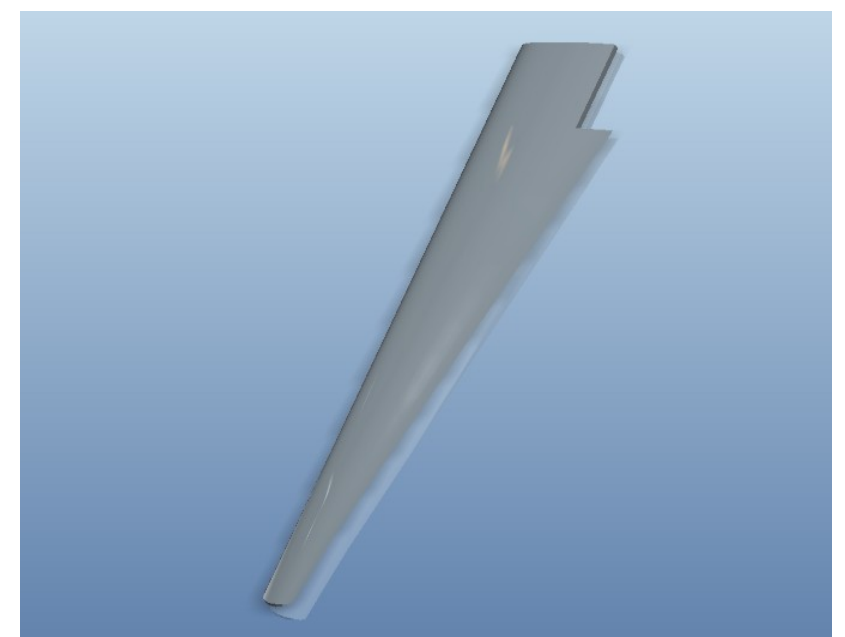

Figure 7. Isometric view of Finalized Normal blade

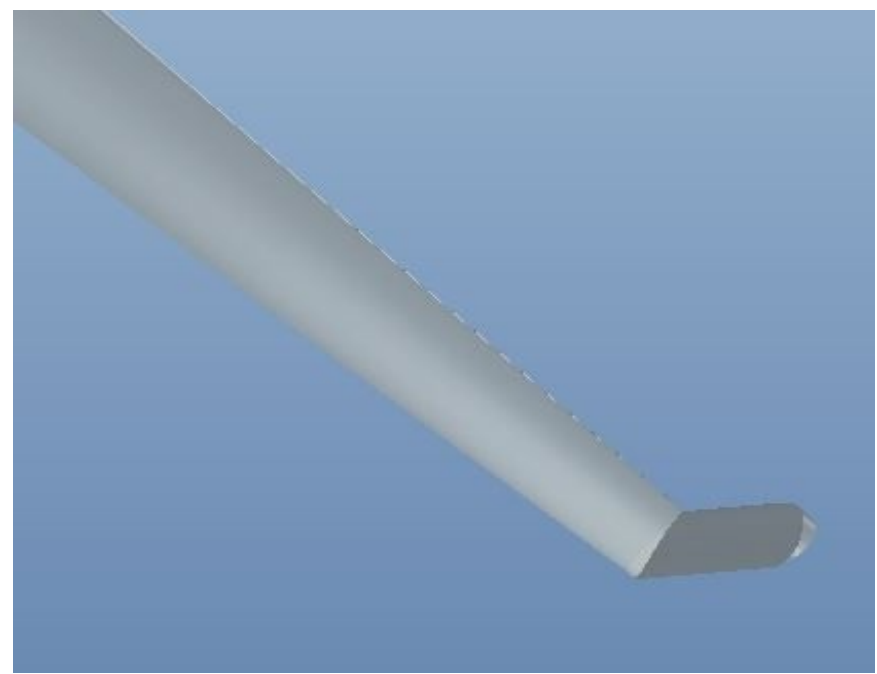

Figure 8. Winglet design 


\subsection{SIZING AND PARAMETERS}

\section{Final Design With Winglet}

There are several sizing aspects involved in the design of a wind turbine, specifically a wind turbine blade. Based on previous designs and research, an optimal blade design has been used in this work, involving airfoils, twisting, setup, and scaling factors.

The rotor diameter for the wind turbine is 3.0 meters, and the winglet configuration selected will add approximately 0.2 meter to this dimension, depending on the configuration used. This dimension could be altered by changes in one or more characteristics of the winglet.

The design parameters of the winglet that this work involves are height, radius and cant angle.

\subsection{CANT ANGLE}

The cant angle of a winglet has been previously defined in this report. The range of variation for the cant angle for the purpose of this work is from $10^{\circ}$ to $90^{\circ}$.

\subsection{RADIUS (Percentage of Height)}

The radius between the turbine blade and the winglet varies as a function of the winglet height; therefore the parameter setup for this case is a multiple of the height. The radius varies from $10 \%$ to $100 \%$ of the height of the winglet,

\subsection{HEIGHT}

The height of the winglet fluctuates in relation with the turbine rotor radius, varying from $1 \%$ to $2 \%$ of the rotor radius. This parameter is setup to change in the range of 0.16 to 0.32 meters.

\section{Final Design}

The blade final design is based on the NACA airfoil family as the preliminary design. The length of the blade changed due to prototyping and testing issues. The new airfoil configuration is shown in Table 4 and Table 5 .

Table 4. Airfoil Station Distribution for Final Blade Design

\begin{tabular}{|c|c|c|c|}
\hline $\mathbf{X}(\mathbf{m})$ & $\mathbf{x} / \mathbf{R}$ & $\begin{array}{c}\text { Twist angle } \\
(\mathbf{d e g})\end{array}$ & $\begin{array}{c}\text { Chord length } \\
(\mathbf{m})\end{array}$ \\
\hline 0 & 0 & 0 & 0.192 \\
\hline 0.18 & 0.474 & 2.5 & 0.172 \\
\hline 0.36 & 0.643 & 5.0 & 0.151 \\
\hline 0.54 & 0.730 & 7.5 & 0.131 \\
\hline 0.72 & 0.783 & 10.0 & 0.111 \\
\hline 0.90 & 0.818 & 12.5 & 0.091 \\
\hline 1.08 & 0.844 & 15. & 0.070 \\
\hline
\end{tabular}

Table 5. Airfoil Configuration

\begin{tabular}{|c|c|c|}
\hline Airfoil & $\mathbf{x} / \mathbf{R}$ & $\mathbf{x} / \mathbf{R ~ x ( m ) ~}$ \\
\hline $63-215$ & 0.3 & 0.48 \\
\hline $63-215$ (Modified) & 0.4 & 0.64 \\
\hline $63-415$ & 0.75 & 1.2 \\
\hline
\end{tabular}

Table 6. Final Winglet Parameters

\begin{tabular}{|c|c|}
\hline Height & 0.15 meters \\
\hline Radius & 0.05 meters \\
\hline Cant Angle & 60 degrees \\
\hline
\end{tabular}




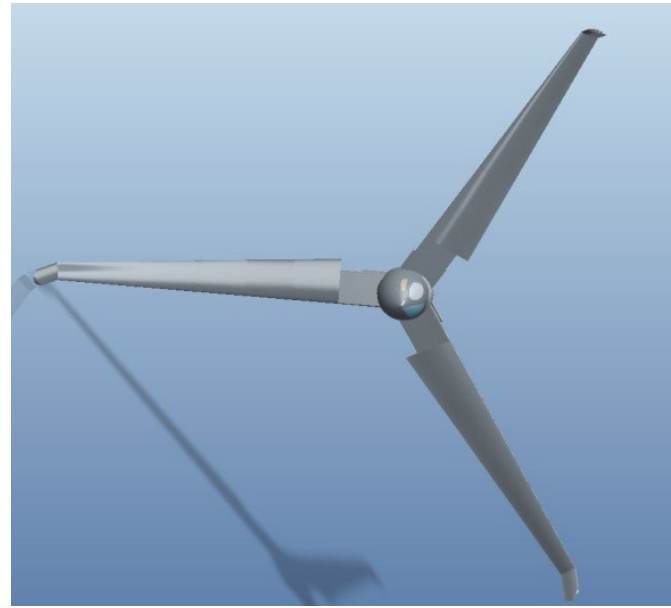

Figure 9. Winglet blade with hub

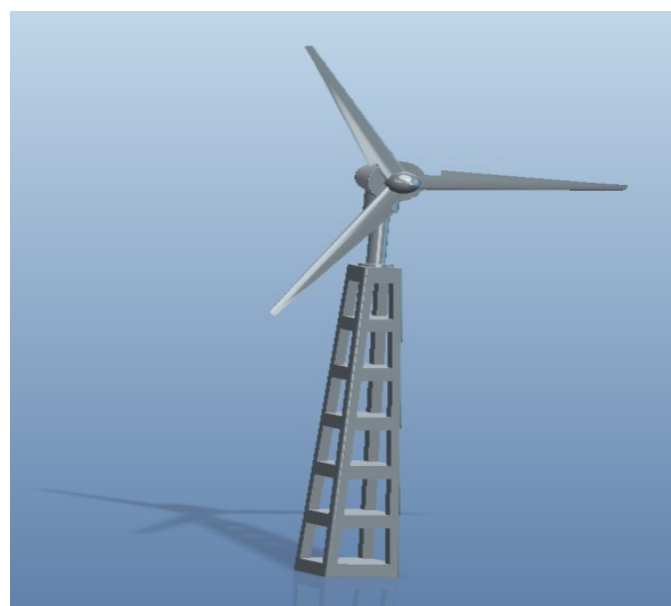

Figure 10. Assembled view of Present design

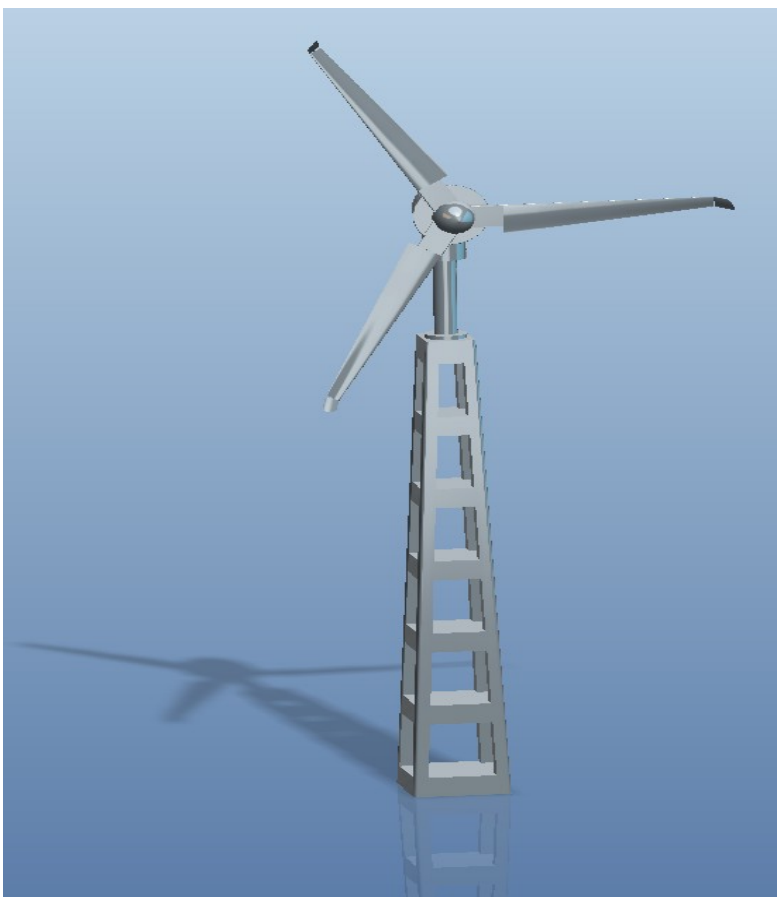

Figure 11. Assembled view of new design (Winglet) 


\section{Result}

Generic model developed could take different shapes and sizes with the help associated parameters and could be used in the pre-design stage of winglets, where spending more time in the design process can be minimized. All the winglets developed in this work are designed according with the design criteria provided by the respective research papers and so there will be no need for designing a specific type of winglet from the base, when this model has been used.

\subsection{Future Work}

The results presented in this work is designing the winglet, a flow analysis could be done in order to determine the lift-off performanceassociated with size of winglet.Based on the type of analysis, user interface can be created. If the analysis is to be done on designed model. Upon changing the values in excel the PRO/E model should change its geometry.

Similarly, for CFD method analysis, software like ANSYS with CFX should be linked with PRO/E. So an actual lifts and drag reduction, vortex effects for the respective winglet can be calculated by varying the parameters. Optimization of the geometry for each type of winglet could be done, by targeting drag as minimizing factor.

\section{References}

[1] Johansen, J. and Sorensen, N.N., "Numerical Analysis of Winglets on Wind Turbine Blades using CFD", EWEC 2007 Conference proceedings, Madrid, Spain, 2007.

[2] Karam Y, Hani M, "Optimal frequency design of wind turbine blades", Journal of Wind Engineering and Industrial Aerodynamics 90 (2002) 961-986.

[3] K.J.Jackson, et al., "Innovative design approaches for large wind turbine blades", 43 ${ }^{\text {rd }}$ AIAA Aerospace Sciences Meeting and Exhibit 10 - 13 January 2005, Reno, Nevada.

[4] Maughmer, M.D, "The Design of Winglets for High-Performance Sailplanes", AIAA 2001-2406, AIAA Applied Aerodynamics Conference, 19th, Anaheim, CA, June 11-14, 2001.

[5] Mickael Edon, "38 meter wind turbine blade design, internship report"

[6] M. Jureczko, M. Pawlak, A. Mezyk, "Optimization of wind turbine blades“, Journal of Materials Processing Technology 167 (2005) 463-471.

[7] Philippe Giguere and Selig, "Blade Geometry Optimization For The Design Of Wind Turbine Rotors" AIAA-2000-0045.

[8] Tingting Guo, Dianwen Wu, Jihui Xu, Shaohua Li, "The Method of Large-scale Wind Turbine Blades Design Based on MATLAB Programming", IEEE.

[9] Wang Xudong, et al., "Blade optimizations for wind turbines", Wind Energy. 2009; 12:781-803, Published online 29 April 2009 in Wiley Interscience.

[10] Z.L. Mahri, M.S. Rouabah, "Calculation of dynamic stresses using finite element method and prediction of fatigue failure for wind turbine rotor" Wseas Transactions On Applied And Theoretical Mechanics, Issue 1, Volume 3, January 2008. 